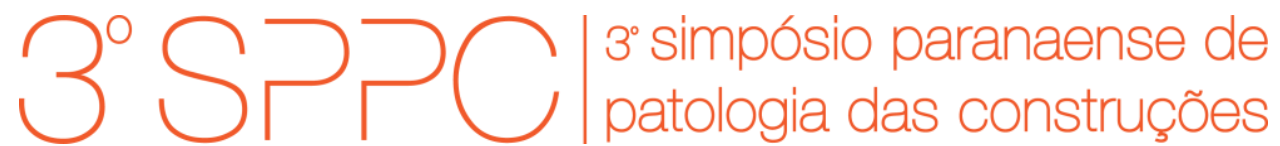

ISSN 2526-7248 artigo n. 3SPPC1005, pp. 47-59, 2018

\title{
Desempenho de edificações produtos do Programa Minha Casa Minha Vida no Alto Sertão da Paraíba: uma visão de consumidores
}

\author{
Queiroga, Lucas Almeida de ${ }^{1}$; Aquino Filho, Gastão Coelho de ${ }^{2}$ \\ ${ }^{1}$ Graduando, Instituto Federal da Paraíba, lucas_queiroga@hotmail.com.br \\ ${ }^{2}$ Mestre, Instituto Federal da Paraíba, gascoelho@hotmail.com
}

\begin{abstract}
Resumo: O déficit habitacional urbano é um problema que aflige o Brasil desde a revolução de 1930, com o deslocamento de grande parte da população rural para as cidades. Devido a essa excessiva expansão urbana, houve uma demasiada demanda por habitações que não foi suprida pelo mercado. Hoje, o governo vem tentando amenizar esse problema, organizando políticas públicas de modo a simplificar o acesso da população de baixa renda à moradia digna, a exemplo do Programa Minha Casa Minha Vida (PMCMV) que promove facilidade financeira na aquisição da casa própria. No entanto, esse fato frequentemente é acompanhado de obras equivocadas, sem estudos prévios. Esses detalhes podem gerar um mau desempenho da edificação, com a manifestação de patologias construtivas que afetam tanto a durabilidade da obra como o conforto de seus moradores. Com o intuito de promover um levantamento de dados a respeito desse assunto, foi realizada uma pesquisa com os beneficiários do PMCMV, a fim de atentar para as suas principais queixas a respeito da situação de degradação da edificação. Após a coleta de dados, o auxílio de um software estatístico foi imprescindível para o entendimento do quadro atual em que se encontra essas habitações. Os resultados mostraram que, dentre os elementos que constituem uma edificação, o sistema estrutural e de revestimento são os mais afetados. Além disso, também foi possível analisar através de estudos estatísticos que tais manifestações patológicas são provenientes, geralmente, de erros construtivos ou de projeto, sendo os causados por utilização em menor escala.
\end{abstract}

Palavras-chave: Patologia das construções, Déficit habitacional, Programa Minha Casa Minha Vida.

Abstract: The urban housing deficit is a problem that has afflicted Brazil since the revolution of 1930 , with the displacement of a large part of the rural population to the cities. Due to this excessive urban sprawl, there was too much demand for housing that was not supplied by the market. Today, the government has been trying to alleviate this problem by organizing public policies in order to simplify the access of the low-income population to decent housing, such as the Programa Minha Casa Minha Vida (PMCMV), which promotes a financial facility for home ownership. However, mistaken works, without previous studies, often accompany this fact. These details can generate a poor performance of the building, with the manifestation of constructive pathologies that affect both the durability of the work and the comfort of its residents. In order to promote a data collection on this subject, a survey was carried out with the beneficiaries of the PMCMV, in order to attend to their main complaints regarding the degradation situation of the building. After the data collection, the aid of statistical software was essential for understanding the current situation in which these dwellings are located. The results showed that, among the elements that constitute a building, the structural and coating system are the most affected, in addition, it was also possible to analyze through statistical analysis that such pathological manifestations are usually derived from constructive or design errors, those caused by use on a smaller scale.

Keywords: Pathology of buildings, Housing deficit, Programa Minha Casa Minha Vida. 
QUEIROGA, L. A. de; AQUINO FILHO, G. C. de, DESEMPENHO DE EDIFICAÇÕES PRODUTOS DO PROGRAMA MINHA CASA MINHA VIDA NO ALTO SERTÃO DA PARAÍBA: UMA VISÃO DE CONSUMIDORES. $3^{\circ}$ Simpósio Paranaense de Patologia das Construções (30 SPPC), artigo 3SPPC1005, pp. 47 - 59, 2018. DOI: 10.4322/2526-7248.005

\section{Introdução}

Desde os primórdios da humanidade, o indivíduo busca por um abrigo no qual possa suportar as variações do meio e seja um amparo para si mesmo e sua família. Desse modo, o ser humano vem buscando aperfeiçoar suas técnicas para garantir conforto e segurança em um só lugar. Com isso, as construções foram evoluindo com o passar dos anos, ao passo que os estudos na área da Engenharia Civil foram sendo intensificados.

De acordo com LICHTENSTEIN [3], a preocupação com a qualidade das edificações teve início juntamente com o surgimento da necessidade de construir, à medida que os moradores constatavam desempenho deficiente na construção. Assim sendo, foi criado um ramo da engenharia para o estudo dessas disfunções encontradas nas obras: a Patologia das Construções.

Com a demanda por moradia digna acentuando-se, foi intensificada a garantia disso pelo governo, tendo em vista que o mesmo tem por obrigação, como poder executivo, de administrar o país de forma a garantir a qualidade de vida da população. Portanto, é necessária a criação de ferramentas que possam auxiliá-lo nessa tarefa, visto que a aquisição da casa própria decente nem sempre é possível devido à desigualdade social.

Uma dessas ferramentas é o Programa Minha Casa Minha Vida, criado pelo Governo Federal em 2009, com o intuito de tornar a moradia acessível às famílias com renda até $R \$ 1.600,00$, criando condições de compra razoáveis que se adequam à receita dos beneficiários, através de financiamentos junto à Caixa Econômica Federal e, mais atualmente, também ao Banco do Brasil em parceria com municípios, estados, empresas e entidades sem fins lucrativos. O objetivo desse programa é reduzir o déficit habitacional brasileiro.

Segundo PINA [4], os projetos devem ajustar-se a NBR 15575: 2013 - Desempenho de edificações habitacionais, para assegurar um controle de qualidade. No entanto, casos de irregularidade nas residências abrangidas pelo programa são bastante evidentes, até mesmo no primeiro ano de uso. Esses fatos podem ser ocasionados pela falta de mão de obra qualificada, fiscalização deficiente ou má qualidade dos produtos usados.

A facilidade de obtenção da casa própria por meio dessa plataforma intensificou bastante o crescimento urbano das cidades, esse crescimento por muitas vezes agilizou o processo de construção, deixando a segurança e a qualidade da obra em segundo plano, gerando imperfeições nas práticas construtivas, o que ocasionou um produto final com um desempenho abaixo do esperado.

Como revela THOMAZ [5], países emergentes, como a exemplo do Brasil, detém de um sistema socioeconômico que exige construções rápidas, o que acarreta em um menor rigor na qualidade dos serviços e materiais utilizados. Esse fato, juntamente com a realidade de uma formação de engenheiros e arquitetos, por vezes, ineficiente, os desvios que ocorrem nos recursos no Estado e as políticas habitacionais implementadas pelo governo, a exemplo do PMCMV, ocasionam uma queda na qualidade das edificações, chegando a algumas serem condenadas antes mesmo da ocupação. 
Para que se tenha um melhor entendimento da problemática, é necessário um estudo específico, para que possam ser identificadas quais patologias são mais comumente detectadas e tentar compreender suas origens, para então buscar soluções e prevenções aos problemas apresentados.

Com esse pensamento, o presente trabalho teve por finalidade consultar parte dos moradores beneficiários do PMCMV no alto sertão da Paraíba, com a intenção de avaliar seus níveis de satisfação para com suas residências, além de identificar os problemas atentados por eles desde a entrega do produto.

\section{Referencial teórico}

\subsection{Patologia das construções}

De acordo com GRANATO [2] inspecionar, avaliar e diagnosticar as patologias em uma edificação é de fundamental importância e são ações que devem ser praticadas costumeiramente, de modo a auxiliar nas manutensões necessárias para o bom desempenho da construção. . Já LICHTENSTEIN [3] afirma que um trabalho de Patologia deve seguir as seguintes diretrizes: primeiramente, utilização de ferramentas de investigação para identificação das falhas; posteriormente, 0 reconhecimento dos tipos de falhas mais comuns e levantamento das medidas de intervenção a serem aplicadas.

As causas dessas imperfeições são dadas por erros ocorridos tanto na fase da concepção do projeto e construção da edificação, como também após a ocupação da habitação. Os dois primeiros são os principais responsáveis, ocorrendo por meio de recalque de fundações, expansão de armadura, uso de materiais inadequados, que são responsabilidades da construtora. No entanto, tais problemas podem ter soluções simples, que podem ser implantadas na execução da obra, a exemplo das estruturas de concreto armado no ambiente urbano, onde os problemas com corrosão são comuns. Um aumento no revestimento da armadura de 2,0 $\mathrm{cm}$ para $2,5 \mathrm{~cm}$ implica no prolongamento da vida útil da armação de 50 para 78 anos, equivalente a um acréscimo de $56 \%$. Esse aumento na durabilidade das habitações seria um ponto positivo tanto para os moradores como para o governo, dado que ocorreria uma redução nos custos com manutenção e reparação [4].

\subsection{Programa Minha Casa Minha Vida}

O déficit habitacional é um problema social que atinge o Brasil há muito tempo. Com seu crescimento, acaba por provocar a insalubridade das cidades, com a falta de infraestrutura e saneamento básico. Diante disso, em 2009 o governo federal lançou uma política pública que iria facilitar o acesso das famílias com baixa renda à aquisição da casa própria, o Programa Minha Casa Minha Vida, baseado na Política Nacional de Habitação.

Com o apoio da Caixa Econômica Federal, sendo esta a executora do projeto Minha Casa Minha Vida, a União busca melhorar a situação habitacional do país promovendo financiamento na aquisição da casa própria para famílias carentes nas áreas urbanas e rurais. De acordo com DAMICO [1], no início, o projeto visava construir 400 mil casas para famílias com renda mensal de até 3 salários mínimos; 
mais 400 mil moradias para famílias com renda entre 3 e 6 salários mínimos e 200 mil residências para famílias com mais de 6 salários mínimos.

Segundo DAMICO [1] uma moradia digna influencia em diversos aspectos, como, por exemplo, a mortalidade infantil, pobreza, patrimônio familiar, além de incentivar a poupança. Desse modo, o programa tem por consequência, melhorar a saúde e o bem-estar da população e aumentar o desenvolvimento econômico do país.

No entanto, para que os objetivos sejam alcançados, é necessário que as obras ocorram de maneira correta, seguindo as recomendações da NBR 15575 (ABNT, 2013), que regulamentam os requisitos para sistemas estruturais, de pisos, de vedações verticais externas e internas, de coberturas e hidros sanitários.

\section{Método de pesquisa}

O presente trabalho foi realizado em três etapas:

- $\quad$ ETAPA 1: Com o crescente número de obras de caráter unifamiliar, devido justamente ao PMCMV, a demanda por espaço físico se intensificou, favorecendo a criação de loteamentos para atender a essa necessidade. Portanto, a princípio, foi necessário pesquisar comunidades habitacionais que são produtos do programa na cidade de Cajazeiras, localizada no Alto Sertão da Paraíba, a fim de facilitar a pesquisa feitam em campo. Essa etapa também inclui a definição do roteiro de pesquisa a ser feito, bem como a elaboração do questionário que será aplicado aos beneficiários, levando em consideração que o público-alvo são leigos quanto as definições técnicas, devendo assim, ser um questionário de fácil entendimento.

- $\quad$ ETAPA 2: Realização da pesquisa em campo nas áreas definidas na etapa anterior. Foram consultados os beneficiários do programa em análise. Eles foram questionados a respeito das patologias que puderam ser observadas pelos mesmos em suas moradias, bem como o tempo mínimo até que foram notados os primeiros sintomas. Também foi avaliado o nível de satisfação dos habitantes e sua pretensão em trocar de moradia futuramente.

- $\quad$ ETAPA 3: Foram processados os dados coletados em campo, com o auxílio de ferramentas estatísticas, a exemplo de gráficos, para entender as principais patologias que afetam essas habitações e o nível de satisfação dos moradores. Esse processamento foi feito com a assistência do software para análises estatísticas SPSS®.

\section{Resultados}

A pesquisa se concretizou com a aplicação de 52 questionários no município de Cajazeiras. O questionário foi desenvolvido por meio de perguntas aos moradores, de forma que abordasse uma linguagem confortável a ambas as partes, de modo a reduzir possíveis dúvidas por parte dos residentes. O Loteamento Cristal (Figura 1) foi o definido como o território a ser estudado. 


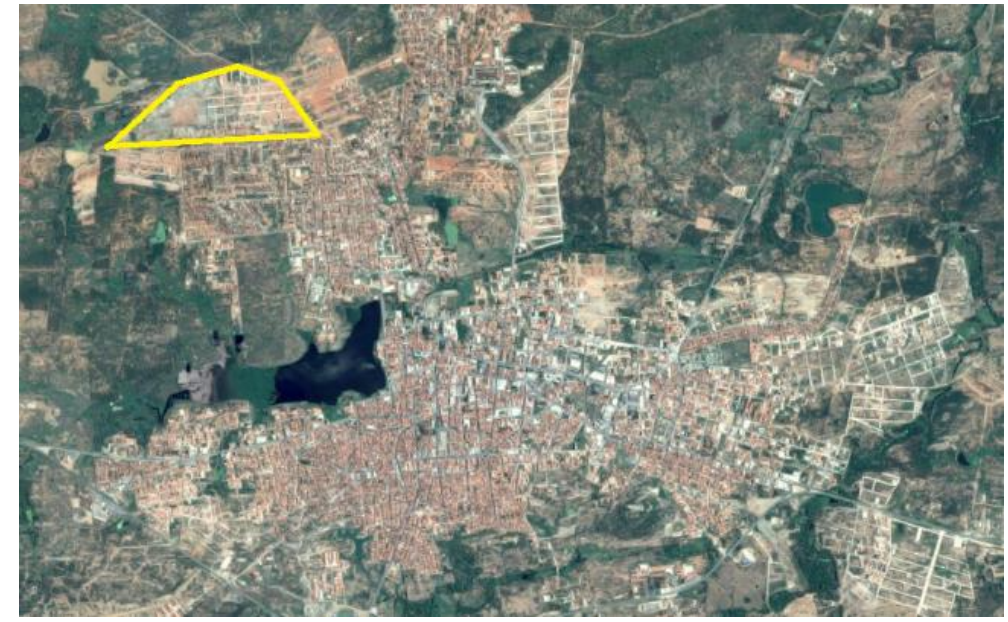

Figura 1: Localização do Loteamento Cristal em Cajazeiras - PB

\subsection{Considerações gerais}

Alguns fatores importantes podem influenciar no resultado da pesquisa realizada, a exemplo da falta de conhecimento técnico por parte dos moradores. Mesmo a pesquisa discorrendo de forma a ter um bom entendimento, grande parte dos pesquisados se mostravam leigos quanto ao assunto, o que pôde ter gerado alguns desentendimentos. Um bom exemplo desse fato é que, por muitas vezes, problemas como "bicheiras", eflorescências e manchas oriundas de infiltrações eram confundidas pelos moradores, levando o aplicador da pesquisa a usar de seu conhecimento técnico e utilizar de outras perguntas para ter certeza de qual manifestação se tratava.

Outro aspecto importante a ser ressaltado é o fato de o interesse em mudar de endereço futuramente, apontado pela pesquisa não condizer com a realidade dos moradores. Situação essa já esperada, pelo fato de que grande parte dos moradores ainda estarem quitando o processo de financiamento da casa, se vendo obrigados a permanecer no local, mesmo em condições de insatisfação com a construção. Era declarado por parte dos residentes que a realização do sonho da casa própria os deixou vulneráveis quanto a uma melhor análise no momento de entrega da habitação quanto às condições da mesma. Com o tempo de moradia e o aparecimento das manifestações patológicas foi percebido a real situação, causando desconforto e até arrependimento quanto à aquisição do imóvel. No entanto, por se tratar de um financiamento longo, muitos não têm condições de procurar outro lugar para viver mais adequadamente.

Além das questões já citadas, uma pequena parte dos entrevistados mostraram um certo nível de receio ao responder as perguntas, mesmo sendo explicado que o intuito da pesquisa era apenas de coleta de informações. Essa circunstância pode causar certo desvio da realidade na apuração dos dados.

Juntamente com os problemas apontados pelos moradores em relação às habitações, também foi relatado o frequente acontecimento de transtornos derivados do loteamento. Transtornos esses que mantinham estreitas ligações com as falhas presentes nas moradias. Alguns exemplos bem evidentes são: 
QUEIROGA, L. A. de; AQUINO FILHO, G. C. de, DESEMPENHO DE EDIFICAÇÕES PRODUTOS DO PROGRAMA MINHA CASA MINHA VIDA NO ALTO SERTÃO DA PARAÍBA: UMA VISÃO DE CONSUMIDORES. $3^{\circ}$ Simpósio Paranaense de Patologia das Construções (30 SPPC), artigo 3SPPC1005, pp. 47 - 59, 2018. DOI: 10.4322/2526-7248.005

- Rotineiras reclamações quanto ao sistema de coleta de esgoto, que apresentava problemas como: entupimentos e vazamentos, aliados a má qualidade do revestimento das ruas (Figura 2);

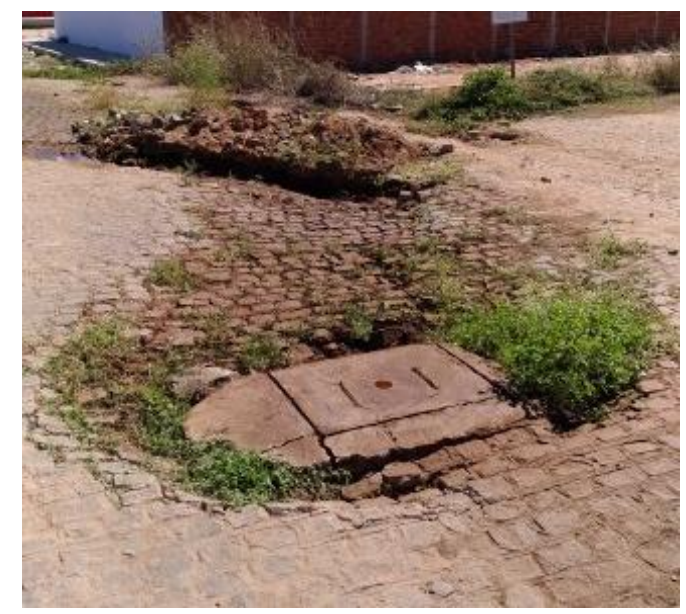

Figura 2: Falha no calçamento e esgoto

- Retorno do esgoto para dentro das residências, principalmente em casos de chuva, o que mostra que não há uma separação de projeto de esgoto e águas pluviais;

- Deficiência no sistema de drenagem, ocasionando alagamentos no período de chuvas, associado a topografia bastante irregular em alguns pontos, com ruas com declividade acima da permitida (Figura 3);

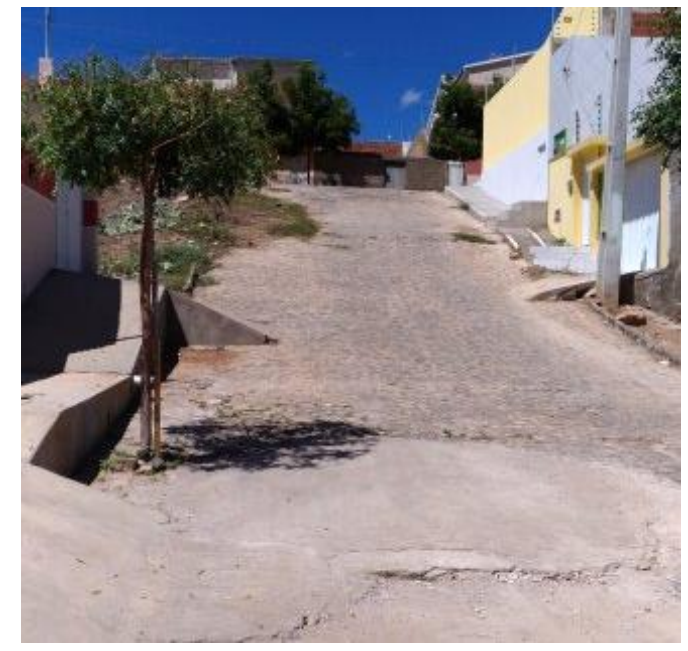

Figura 3: Rua com alta declividade

- Utilização de restos de demolição como aterro, geralmente de edificações antigas, acarretando aparecimento de cupins e provocando instabilidade no solo a ser construído, o que pode ter sido causa do aparecimento de trincas e rachaduras em boa parte das habitações;

- Sistema elétrico de má qualidade provocando rotineiras quedas de energia e problemas na instalação dos padrões de entrada das edificações. 
QUEIROGA, L. A. de; AQUINO FILHO, G. C. de, DESEMPENHO DE EDIFICAÇÕES PRODUTOS DO PROGRAMA MINHA CASA MINHA VIDA NO ALTO SERTÃO DA PARAÍBA: UMA VISÃO DE CONSUMIDORES. $3^{\circ}$ Simpósio Paranaense de Patologia das Construções (30 SPPC), artigo 3SPPC1005, pp. 47 - 59, 2018. DOI: 10.4322/2526-7248.005

\subsection{Dados}

Os dados coletados através dos questionários foram analisados com auxílio do software IBM SPSS Statistics.

\subsubsection{Tipos de manifestações patológicas}

Com relação aos tipos de manifestações patológicas mais presentes nas edificações estudadas, optou-se por se construir um gráfico de barras mostrando a frequência de aparecimento de cada sistema construtivo (Figura 4 e 5):

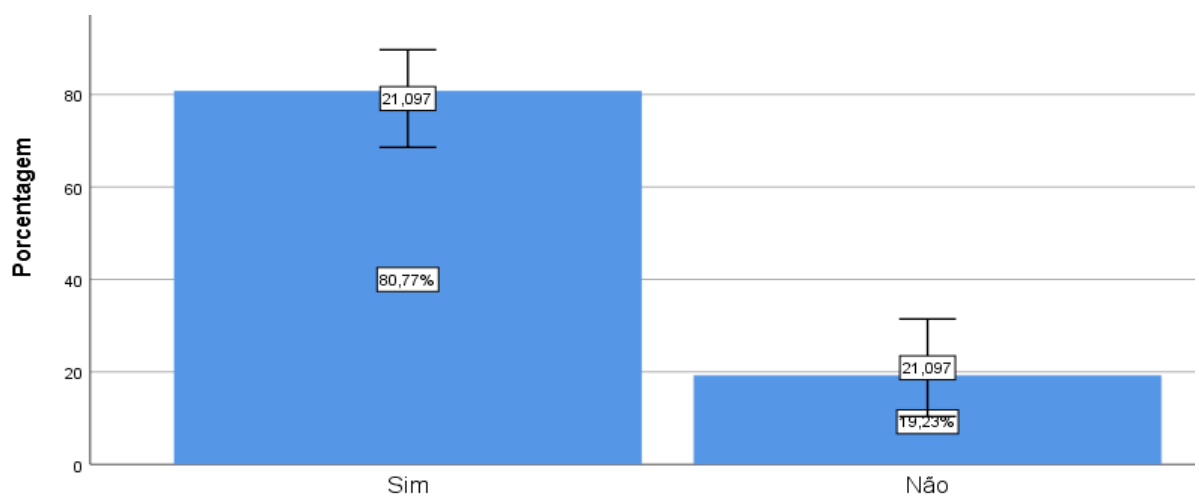

Estrutura

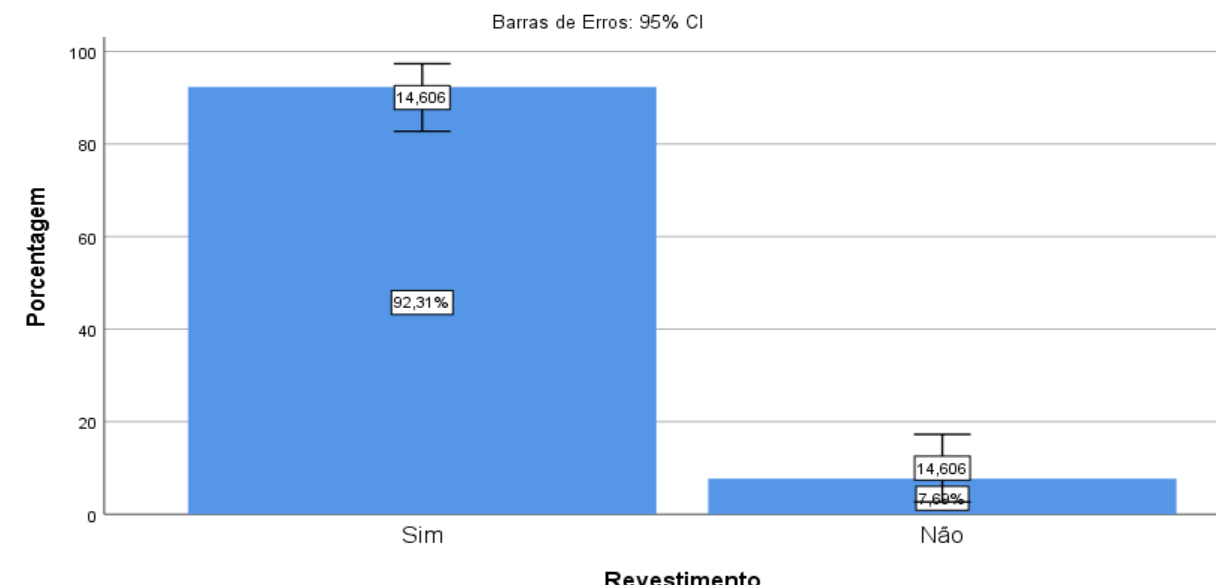

Barras de Erros: $95 \% \mathrm{Cl}$

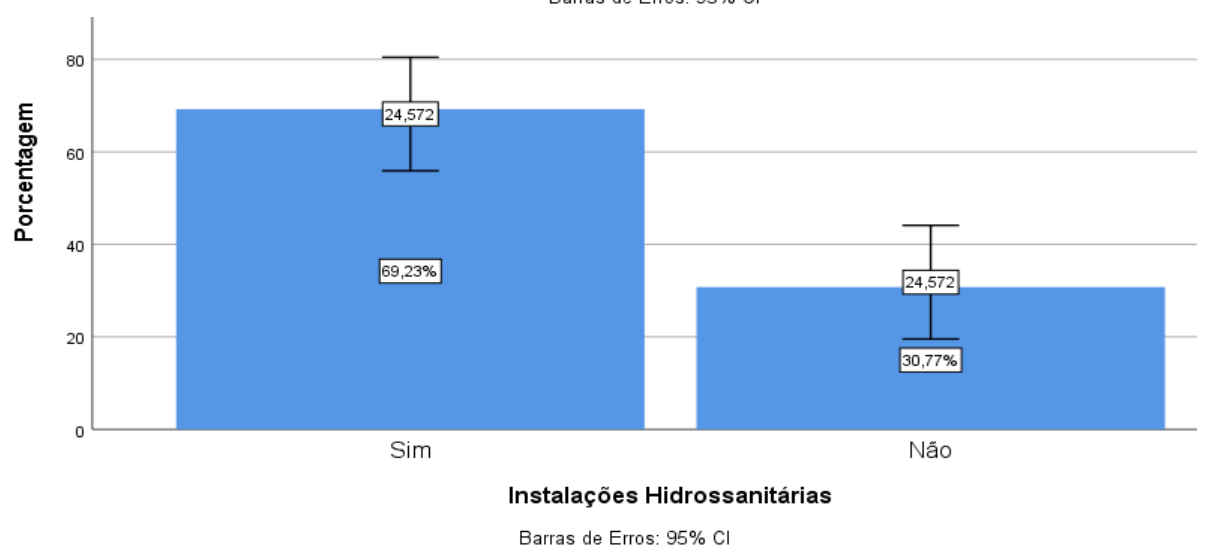

Figura 4: Presença de patologias nos sistemas estrutural, de revestimento e hidrossanitário em

Cajazeiras - PB 
QUEIROGA, L. A. de; AQUINO FILHO, G. C. de, DESEMPENHO DE EDIFICAÇÕES PRODUTOS DO PROGRAMA MINHA CASA MINHA VIDA NO ALTO SERTÃO DA PARAÍBA: UMA VISÃO DE CONSUMIDORES. $3^{\circ}$ Simpósio Paranaense de Patologia das Construções (30 SPPC), artigo 3SPPC1005, pp. 47 - 59, 2018. DOI: 10.4322/2526-7248.005
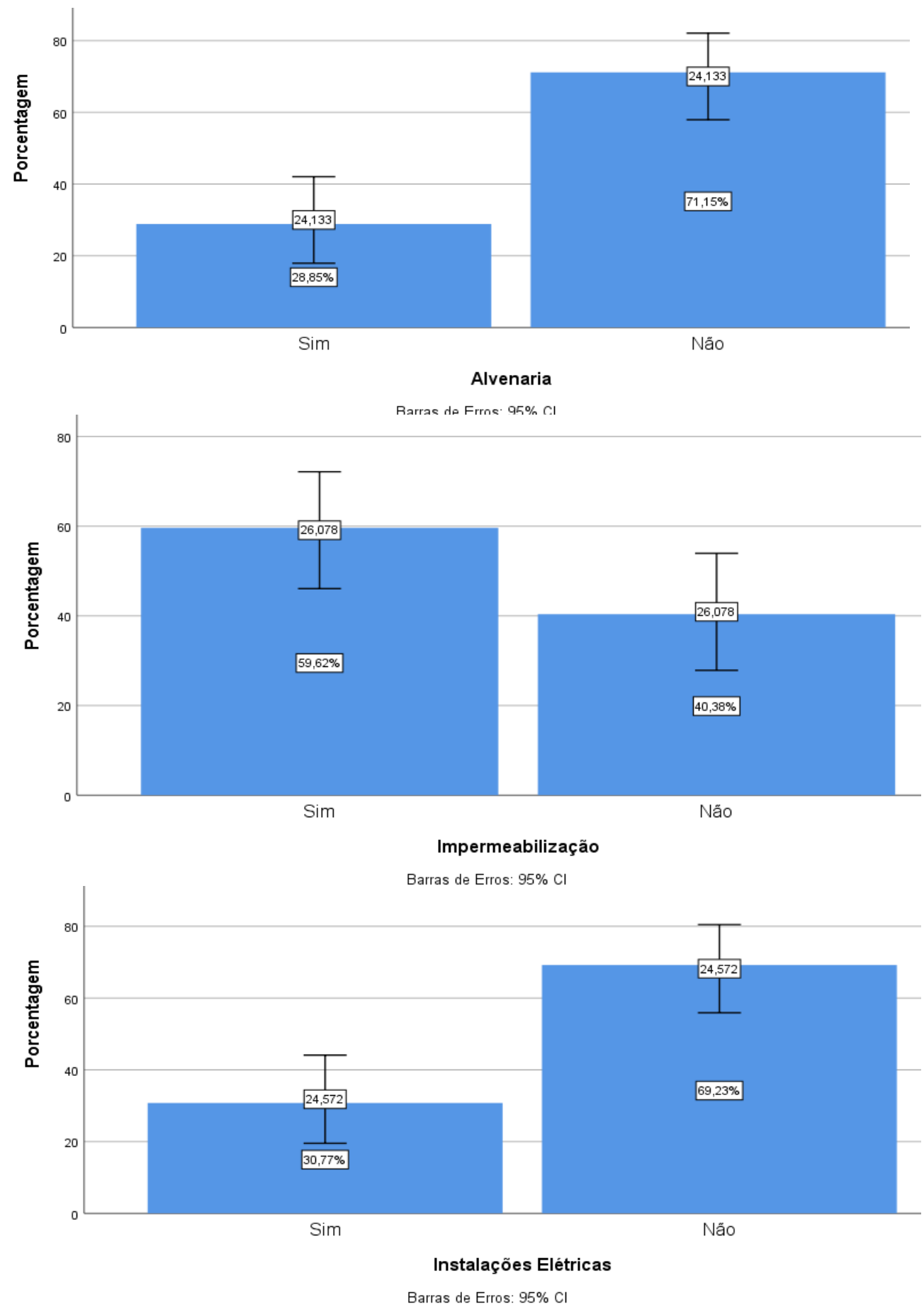

Figura 5: Presença de patologias nos sistemas de alvenaria, impermeabilização e elétrico em Cajazeiras - PB

Com esses dados, torna-se notória a predominância de patologias de revestimento em relação aos outros tipos, atingindo cerca de $92 \%$, seguida pelas patologias estruturais, alcançando um valor em torno de $80 \%$.

No tocante às queixas principais dos moradores a cerca dos defeitos mais recorrentes foram mencionados os seguintes pontos:

- $\quad$ Estrutura: Trincas (Figuras 6 e 7) e eflorescências (Figura 8);

- Revestimento: Deteriorização da tinta e trincas em cerâmicas (Figuras 9 e 10); 
QUEIROGA, L. A. de; AQUINO FILHO, G. C. de, DESEMPENHO DE EDIFICAÇÕES PRODUTOS DO PROGRAMA MINHA CASA MINHA VIDA NO ALTO SERTÃO DA PARAÍBA: UMA VISÃO DE CONSUMIDORES. $3^{\circ}$ Simpósio Paranaense de Patologia das Construções (30 SPPC), artigo 3SPPC1005, pp. 47 - 59, 2018. DOI: 10.4322/2526-7248.005

- Impermeabilização: Infiltração (Figuras 11, 12 e 13);

- Instalações hidrossanitárias: Entupimento de esgoto, abastecimento deficiente de água fria e captação pluvial ineficiente;

- Instalações elétricas: Falhas em tomadas, sistema SPDA ineficiente ou inexistente.

Muitos problemas tiveram tentativa de solução, por parte dos próprios moradores ou construtores, no entanto, a maioria sem solucionar totalmente o problema.
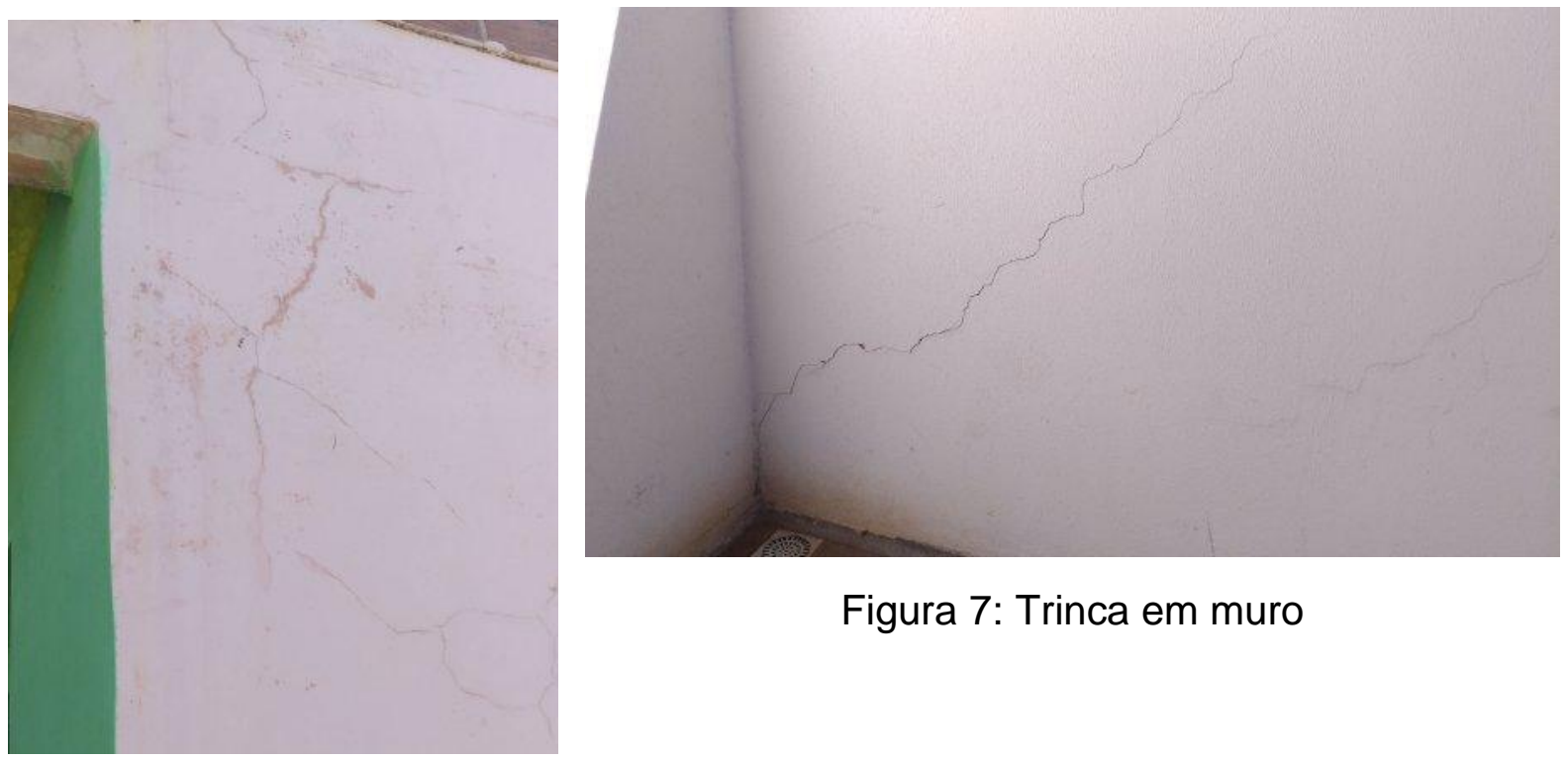

Figura 7: Trinca em muro

Figura 6: Trincas em alvenaria

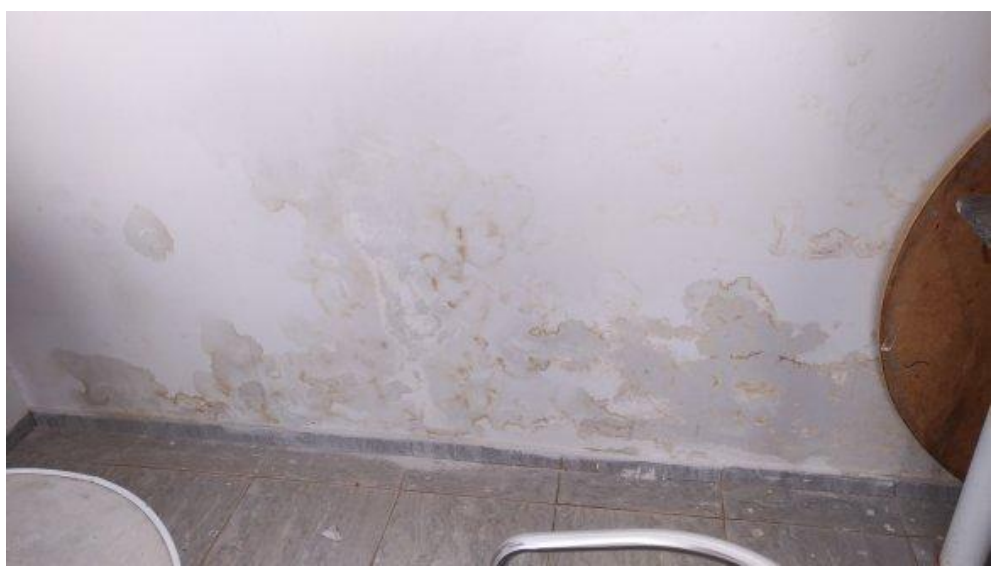

Figura 8: Eflorescência

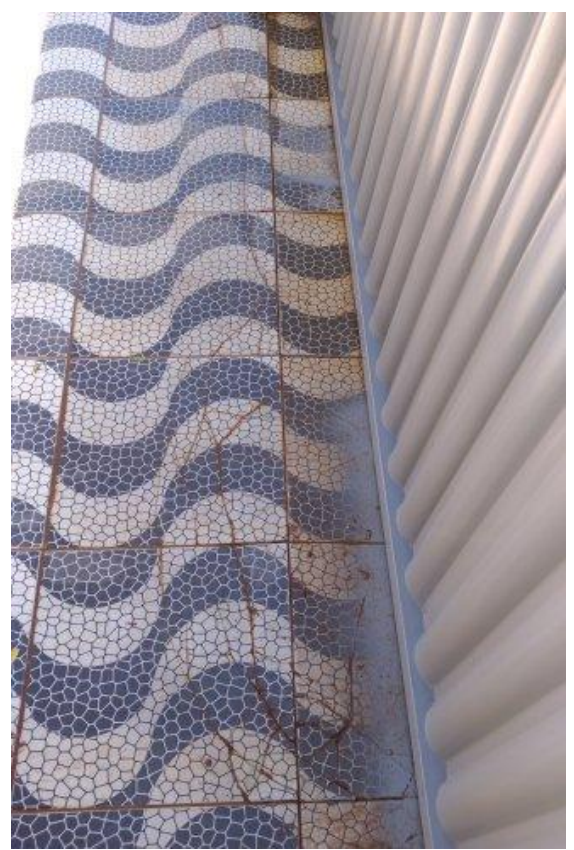

Figura 9: Piso cerâmico trincado devido a recalque 


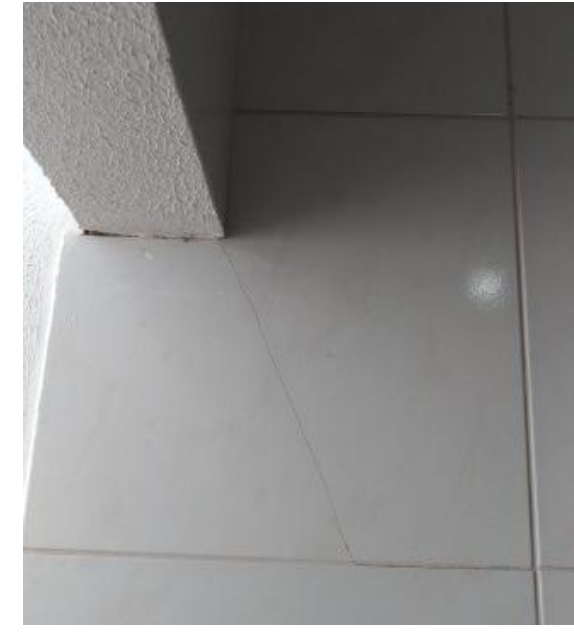

Figura 10: Cerâmica trincada devido à falta de juntas de movimentação

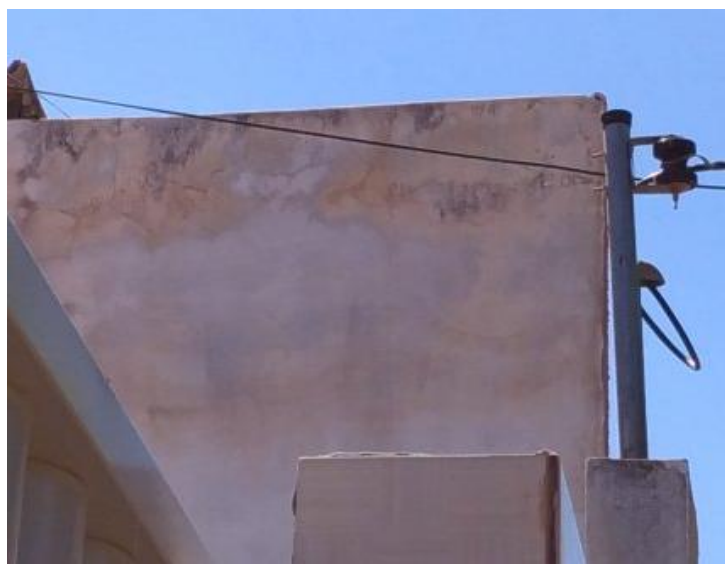

Figura 12: Infiltração ocasionada por umidade da chuva

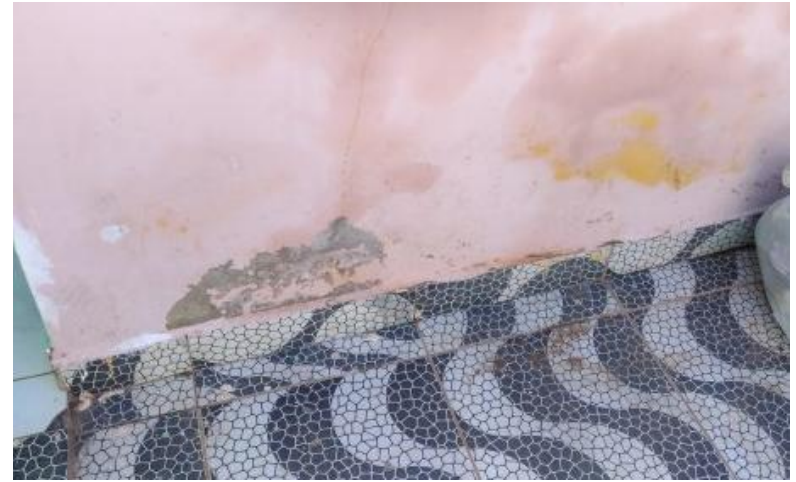

Figura 11: Infiltração ocasionada por umidade do solo

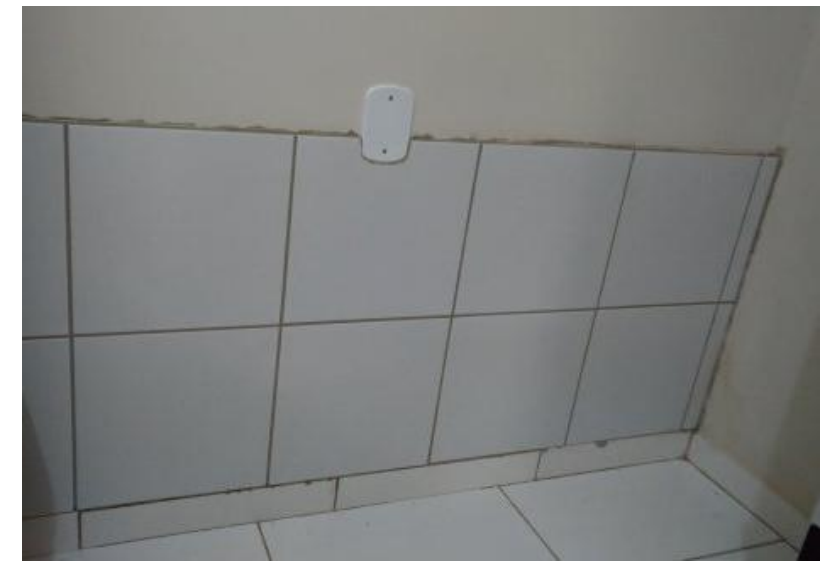

Figura 13: Tentativa errônea de reparar uma infiltração, utilizada por moradores

\subsubsection{Construtores}

Referente aos construtores, os moradores foram questionados sobre dois aspectos: entrega do manual de utilização e conservação no momento da entrega do imóvel e sobre a disponibilidade da empresa responsável pela construção da edificação com respeito à solução dos problemas ocorridos. Com base no que é previsto por lei e pelo regulamento do PMCMV, a construtora deve assegurar uma garantia mínima de cinco anos, arcando com as responsabilidades e custos advindos dos problemas construtivos que surgirem.

Como resultado, $57,7 \%$ dos moradores questionados relataram ter dificuldades no momento de contatar os construtores responsáveis, estes por sua vez, se mostravam indiferentes quanto à situação dos clientes, não solucionando os problemas apresentados ou dando prazos extremamente longos, agravando assim cada vez mais a situação da edificação. Parte dos questionados afirmaram arcar com as despesas com manutenção por chegar a situações críticas, ameaçando a integridade da estrutura. A solução que deveria ser praticada, seria informar ao 
banco responsável pelo financiamento sobre a displicência do construtor, para que sejam tomadas as medidas cabíveis, no caso de futuras obras por parte da mesma empresa. No entanto, os residentes mantinham certo receio quanto à essa solução, pelo fato de causar desentendimentos entre eles e os construtores.

Um fator que poderia diminuir o aparecimento das patologias, seria a entrega de um manual de utilização de conservação da edificação aos moradores, sendo uma recomendação do PMCMV, porém geralmente não é aplicada, aumentando os riscos de uma má utilização do imóvel, acarretando em possíveis problemas. A tabela a seguir mostra os resultados das respostas dos moradores quando questionados a respeito da entrega desses manuais, como também em quanto tempo surgiram as primeiras patologias, gerando uma tabela de dados cruzados que possibilita avaliar se o fato da entrega dos manuais resulta em aparecimentos mais tardios dos defeitos (Tabela 1).

Tabela 1: Tabulação cruzada - Tempo de aparecimento das primeiras patologias $X$ Entrega de manual de conservação.

\begin{tabular}{|c|c|c|c|c|c|}
\hline & & & Entrega de $\mathrm{m}$ & e conservação & \\
\hline & & & Sim & Não & Total \\
\hline & & Contagem & 2 & 19 & 21 \\
\hline & Menos de 6 meses & $\begin{array}{l}\text { \% em Entrega de } \\
\text { manual de conservação }\end{array}$ & $100,0 \%$ & $38,0 \%$ & $40,4 \%$ \\
\hline & & Contagem & 0 & 15 & 15 \\
\hline $\begin{array}{l}\text { Tempo de } \\
\text { aparecimento }\end{array}$ & Entre 6 meses e 1 ano & $\begin{array}{l}\text { \% em Entrega de } \\
\text { manual de conservação }\end{array}$ & $0,0 \%$ & $30,0 \%$ & $28,8 \%$ \\
\hline das primeiras & & Contagem & 0 & 14 & 14 \\
\hline patologias & Entre 1 anos e 5 anos & $\begin{array}{l}\text { \% em Entrega de } \\
\text { manual de conservação }\end{array}$ & $0,0 \%$ & $28,0 \%$ & $26,9 \%$ \\
\hline & & Contagem & 0 & 2 & 2 \\
\hline & Após 5 anos & $\begin{array}{l}\text { \% em Entrega de } \\
\text { manual de conservação }\end{array}$ & $0,0 \%$ & $4,0 \%$ & $3,8 \%$ \\
\hline & & Contagem & $2(3,8 \%)$ & $50(96,2 \%)$ & 52 \\
\hline Total & & $\begin{array}{l}\text { \% em Entrega de } \\
\text { manual de conservação }\end{array}$ & $100,0 \%$ & $100,0 \%$ & $100,0 \%$ \\
\hline
\end{tabular}

Uma maneira de verificar se duas variáveis nominais têm alguma relação entre si, é aplicando o teste do Qui-quadrado e verificando o nível de significância adotado. Com a aplicação do teste, temos uma significância assintótica (bilateral) de 0,381, que é um valor bastante significativo e maior que 0,05, nível de significância comumente utilizado em pesquisas semelhantes. Por essa razão, não se pode afirmar que a entrega do manual de conservação influencia no tempo de aparecimento das patologias. Além disso, podemos observar que a grande maioria dos defeitos que ocorreram nas edificações, apareceram em menos de um ano $(69,2 \%)$, sendo $40,4 \%$ só no primeiro semestre, o que significa que, muito provavelmente, os problemas originaram na fase de concepção ou execução, por se tratar de um período muito curto para ocasionar problemas devido a ocupação. 
QUEIROGA, L. A. de; AQUINO FILHO, G. C. de, DESEMPENHO DE EDIFICAÇÕES PRODUTOS DO PROGRAMA MINHA CASA MINHA VIDA NO ALTO SERTÃO DA PARAÍBA: UMA VISÃO DE CONSUMIDORES. $3^{\circ}$ Simpósio Paranaense de Patologia das Construções (30 SPPC), artigo 3SPPC1005, pp. 47 - 59, 2018. DOI: 10.4322/2526-7248.005

Outro ponto a exaltar é o fato do número extremamente baixo de casos em que é feita a entrega desse material. Dos 52 questionários aplicados, apenas 2 afirmaram que receberam o manual.

\subsubsection{Nível de satisfação}

O último tópico a ser abordado no questionário foi a respeito do nível de satisfação dos usuários e a pretensão quanto a mudança de endereço. A Figuras 13 mostra o resultado do nível de satisfação dos moradores:

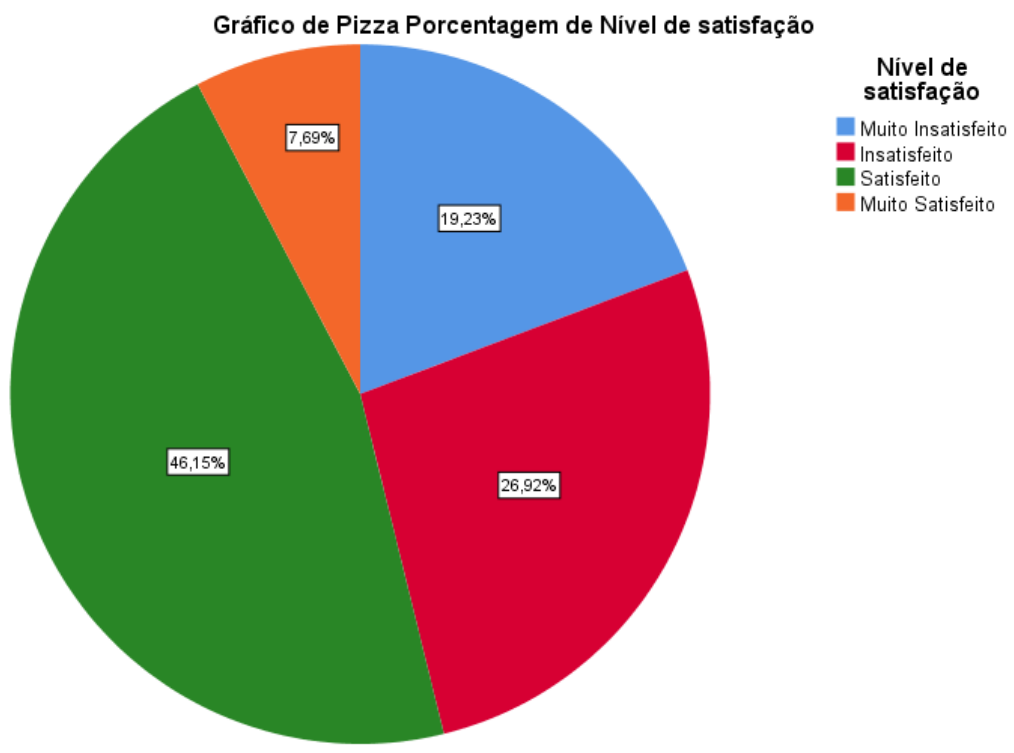

Figura 13: Nível de satisfação dos moradores.

Como é possível notar analisando o gráfico, a pesquisa realizada mostra um quadro de clientes contrariados com o sonho da casa própria, onde o total dos entrevistados que responderam estar muito satisfeitos com a aquisição do imóvel só chegou a 7,69\%, por outro lado, 19,23\% estão muito insatisfeitos com a compra.

Como já foi falado anteriormente, não era esperado que o desejo de mudar de endereço e o nível de satisfação tenham alguma relação, pelo fato de que a maioria dos moradores ainda estão em processo de pagamento, por meio de um financiamento muito longo, que os obriga a viver nas condições em que está. Dessa forma, podemos aplicar o teste Mann-Whitney para avaliar essa teoria, por se tratar de uma variável ordinária. Com a ferramenta IBM SPSS Statistics, chegamos ao resultado de nível de significância para esse teste de 0,072, maior que 0,05, que foi o adotado nessa pesquisa. Nessa situação, podemos comprovar que o nível de satisfação não influencia na decisão de trocar de endereço, portanto os moradores de Cajazeiras se veem obrigados a continuar onde estão, mesmo em condições desfavoráveis. 


\section{Conclusão}

Com o que foi executado, foi possível compreender que o estudo de patologias vai muito além de trincas e fissuras, mas sim, se faz necessária uma abordagem geral de todos os componentes de uma residência para se ter um resultado satisfatório, pois a edificação por completo sempre está sujeita às ações de agentes degradantes. Mesmo não se tratando de problemas que ocasionem a ameaça da integridade física da estrutura, muitas manifestações causam desconforto ao usuário, obrigando-o a viver em um ambiente insalubre. Se tratando de moradias advindas do PMCMV esse problema se agrava, pois, os moradores se veem em uma situação de incapacidade, sendo levados a aceitar as condições de moradia impostas, por ainda não terem quitado completamente a dívida fruto da aquisição do imóvel por meio do financiamento. Sendo por muitas vezes ainda, esquecido pelo responsável da construção da casa, que deve garantir a integridade da residência por cinco anos, ação essa imposta por lei. Com a análise dos dados foi possível uma confirmação da realidade vivida por esses consumidores, que relataram, por meio do questionário respondido, que são inúmeros os problemas que afetam a integridade da residência, deixando bastante a desejar nos quesitos conforto e segurança. Com os dados processados, foi comprovado também, por modelagens estatísticas que as manifestações patológicas presentes são provenientes de erros na fase de execução e concepção, livrando os moradores da culpa do aparecimento desses defeitos.

\section{Agradecimentos}

Agradecimentos especiais ao IFPB - Campus Cajazeiras, pelo apoio e incentivo à pesquisa científica, em especial à Coordenação de Pesquisa e Extensão.

\section{Referências}

[1] DAMICO, Fabiano. O Programa Minha Casa, Minha Vida e a Caixa Econômica Federal. In: O Desenvolvimento Econômico Brasileiro e a Caixa. Rio de Janeiro, 2011. p. 33.

[2] GRANATO, José Eduardo. Patologia das construções. 2002. Acesso em, v. 30, 2017.

[3] LICHTENSTEIN, Norberto B. Patologia das construções. Boletim Técnico, v. 6, p. 86, 1986.

[4] PINA, Gregório Lobo de. Patologia nas habitações populares. 2013. Tese de Doutorado. Universidade Federal do Rio de Janeiro.

[5] THOMAZ, Ercio. Trincas em edifícios: causas, prevenção e recuperação. PINI: Escola Politécnica da Universidade de São Paulo: Instituto de Pesquisas Tecnológicas, 1989. 